\title{
Haemodynamic factors influencing opening snap interval in mitral stenosis
}

\author{
Roland Ebringer, Aubrey Pitt, and S. T. Anderson \\ From Cardiovascular Diagnostic Service, Alfred Hospital, Melbourne, and Monash \\ University Department of Medicine, Melbourne, Victoria, Australia
}

Various haemodynamic measurements were correlated with the A2-OS interval in 35 patients with pure or predominant mitral stenosis.

There was good correlation of left atrial $V$ wave pressure, left ventricular systolic pressure, and mitral mean diastolic gradient with A2-OS. There was no significant correlation of mitral valve area with $A 2-O S$. When the left ventricular pressure was arbitrarily assigned to one particular pressure (100 mm. $\mathrm{Hg}$ ) correlations with all other variables improved. There was still no correlation of $A 2-O S$ interval with mitral valve area.

These and other haemodynamic factors influencing the A2-OS interval are briefly discussed.

In stenotic mitral valve disease an opening snap is often heard after the sound made by the closing of the aortic valve (A2). The opening snap is presumed to be the sound the mitral valve makes on opening at the start of diastole. The time interval between these two sounds (A2-OS) in different patients and under varying conditions in the same patient may range from 0.03 to $0.15 \mathrm{sec}$. (Surawicz et al., 1966). This A2-OS interval when present at phonocardiography has been used to aid clinical assessment of the severity of stenosis. A short A2-OS interval indicates a more severe stenosis than a long interval.

To evaluate the haemodynamic significance of the opening snap, investigators have compared the A2-OS interval with the mean left atrial pressure (LA $\bar{M}$ ), the left atrial ' $V$ ' wave pressure (LA ' $V$ '), the left ventricular or brachial systolic pressure (LV), the mean mitral diastolic gradient, and the mitral valve area as calculated by the formula devised by Gorlin and Gorlin (195I).

Some of these studies have shown a relation between mean left atrial pressure and the A2-OS interval (Bayer, Loogen, and Wolter, 1956; Craige, 1957; Leo and Hultgren, 1959; Delman et al., 1966). They found the higher the mean left atrial pressure the shorter the A2-OS interval. Other studies (Julian and Davies, 1957; Proctor et al., 1958; Di Bartolo, Núñez-Dey, and BendezúPrieto, 1962) have not shown such a clear relation. Some investigators (Julian and Davies, 1957; Rich, 1959; Oriol et al., 1965) Received II August 1969. have indicated that the atrial ' $V$ ' wave pressure was a better indicator and correlated more closely with the A2-OS interval. However, others (Di Bartolo et al., 1962; Davies, 1967) have found that the relation between the A2-OS interval and the ' $V$ ' wave pressure was not significant in their series.

Left ventricular systolic pressure affects the A2-OS interval (Bayer et al., 1956; Julian and Davies, 1957; Oriol et al., 1965) in that the higher the pressure the longer the interval.

Comparisons of mean mitral diastolic gradient and mitral valve area with the $\mathrm{A}_{2}-\mathrm{OS}$ interval have all shown poor correlations (Wells, 1954; Julian and Davies, 1957; Proctor et al., 1958; Di Bartolo et al., 1962; Surawicz et al., 1966).

It is apparent that the existence of a relation between atrial pressure and the A2-OS interval is still in question. We have studied 35 patients with pure or predominant mitral stenosis. Correlations of A2-OS intervals with atrial pressure ' $V$ ', left ventricular pressure, mitral gradient, and mitral valve area were obtained to assess the value of the opening snap interval as an indicator of stenotic severity. Since left ventricular pressures produced such conspicuous changes on the A2-OS interval, a formula was devised to eliminate the effect of varying systolic pressures.

\section{Method}

Studies were made on 39 patients with pure or predominant mitral stenosis. These patients had 
either trivial or no mitral incompetence and trivial or no aortic valve disease. Four patients were eliminated; two of these had no opening snaps and two had incomplete studies. Included in this study, therefore, are 35 patients, of whom 6 did not have their mitral valve areas calculated.

The left atrial ' $V$ ' wave pressures were all measured transseptally except in 2 cases where indirect left atrial pressures were obtained by the pulmonary artery wedge technique. Simultaneous left ventricular pressures were obtained by retrograde aortic catheterization. The pressures were recorded on a Sanborn multichannel mirror galvanometer recorder. The left atrial and left ventricular pressure and pressure gradients were read directly from the recording paper as the output signals were calibrated and corrected to the same sensitivities and used the same baseline.

In the early part of our study simultaneous pressures and phonocardiograms were not available. Where heart rates at phonocardiography were different from heart rates at catheterization the correction method of Wells (1954) was used to bring the A2-OS interval to the value predicted by the heart rate occurring during the measurement of pressures. The A2-OS intervals on the phonocardiograms were read to the nearest 0.01 of a second.

\section{Results}

The haemodynamic findings are listed in Table I. Correlations were performed using the Pearson $r$ Formula and tests of significance were applied. Table 2 shows the relation of the observed A2-OS intervals to various haemodynamic findings. There was a good correlation between the A2-OS interval and the LA ' $V$ ' pressure, left ventricular systolic pressure (LV), and especially with the difference between these two values LV-LA ' $V$ '. The correlation of the A2-OS interval to the mitral diastolic mean gradient was less striking though still significant. There was no correlation between mitral valve area and the A2-OS interval.

Correction of A2-OS for variations in left ventricular pressure As shown in Fig. I, there are three factors which, taken together, determine the length of the A2-OS interval. These are end-systolic left ventricular pressure, the rate of fall of pressure in the left ventricle during the relaxation phase, and the left atrial pressure at the time of the opening of the mitral valve. For practical purposes the left ventricular systolic pressure can represent the end-systolic pressure at point A. The left atrial ' $V$ ' wave pressure can represent the atrial pressure when the mitral valve starts to open at point $B$.

Thus for any one patient a rise in LV pressure will increase A2-OS and a rise in
TABLE I Haemodynamic data and A2-OS interval in 35 cases of mitral stenosis

\begin{tabular}{|c|c|c|c|c|c|c|}
\hline Case No. & $\begin{array}{l}\text { Left ventri- } \\
\text { cular pressure } \\
(\mathrm{mm} . \mathrm{Hg})\end{array}$ & $\begin{array}{l}\text { Left atrial } \\
\text { ' } V \text { ' pres- } \\
\text { sure } \\
(\mathrm{mm} . \mathrm{Hg})\end{array}$ & $\begin{array}{l}\text { Mean } \\
\text { mitral } \\
\text { gradient } \\
(\mathrm{mm} . \mathrm{Hg})\end{array}$ & $\begin{array}{l}\text { Mitral } \\
\text { valve area } \\
\left(\mathrm{cm} .^{2}\right)\end{array}$ & $\begin{array}{l}A 2-O S \\
(s e c .)\end{array}$ & $\begin{array}{l}\text { A2-OS (sec.) } \\
\text { corrected for } \\
\text { systemic } \\
\text { pressuref }\end{array}$ \\
\hline I & 120 & 12 & 5 & $4 \cdot 4$ & 0.07 & 0.07 \\
\hline 2 & 80 & 37 & 28 & $I \cdot 2$ & 0.05 & 0.06 \\
\hline 3 & II 7 & 16 & $7 \cdot 5$ & $1 \cdot 5$ & 0.08 & 0.08 \\
\hline 4 & 100 & 31 & 16 & $1 \cdot 3$ & 0.07 & 0.07 \\
\hline 5 & 112 & 28 & 13 & - & 0.08 & 0.08 \\
\hline 6 & 106 & 22 & 10.5 & $2 \cdot 6$ & 0.07 & 0.07 \\
\hline 7 & 150 & $44^{\star}$ & 12 & $2 \cdot 0$ & 0.06 & 0.04 \\
\hline 8 & 90 & 24 & 9 & $1 \cdot 4$ & 0.05 & 0.05 \\
\hline 9 & 91 & 19 & 14 & $\mathbf{I} \cdot \mathbf{I}$ & 0.05 & 0.05 \\
\hline I0 & 102 & 22 & II & - & 0.06 & 0.06 \\
\hline I I & 124 & 35 & 20 & 0.8 & 0.04 & 0.04 \\
\hline 12 & 90 & 21 & 12 & 0.9 & 0.05 & 0.05 \\
\hline 13 & 147 & 9 & 4 & $4 \cdot 0$ & 0.13 & 0.13 \\
\hline 14 & 133 & 15 & 9 & $2 \cdot 3$ & 0.12 & O.II \\
\hline 15 & 125 & 40 & 19 & $3 \cdot 0$ & 0.05 & 0.04 \\
\hline 16 & II4 & I4 & 6 & $2 \cdot 5$ & 0.09 & 0.09 \\
\hline 17 & 142 & 19 & 6 & $\mathrm{I} \cdot 4$ & 0.10 & 0.09 \\
\hline 18 & 154 & 27 & 9 & 0.9 & 0.10 & 0.09 \\
\hline 19 & IOI & 21 & 13 & $2 \cdot 4$ & 0.09 & 0.09 \\
\hline 20 & 124 & 19 & 6 & $I \cdot 4$ & 0.07 & 0.06 \\
\hline $2 I$ & 107 & 35 & - & - & 0.07 & 0.07 \\
\hline 22 & 102 & 34 & 16 & $I \cdot O$ & 0.06 & 0.06 \\
\hline 23 & 134 & 14 & 5 & $I \cdot 0$ & $0.1 I$ & 0.10 \\
\hline 24 & 121 & 52 & 19 & - & 0.03 & 0.02 \\
\hline 25 & 126 & 27 & I0 & 0.8 & 0.07 & 0.07 \\
\hline 26 & IIO & 19 & IO & 0.5 & 0.07 & 0.06 \\
\hline 27 & 134 & $4 I$ & I I & $1 \cdot 4$ & 0.06 & 0.05 \\
\hline 28 & 95 & 25 & 29 & 2.4 & 0.06 & 0.06 \\
\hline 29 & 135 & 6 & IO & $I \cdot 2$ & 0.12 & 0.12 \\
\hline 30 & 128 & 20 & 9 & $I \cdot O$ & 0.07 & 0.06 \\
\hline 31 & 170 & 26 & 12 & $I \cdot 2$ & 0.13 & $0.1 \mathrm{I}$ \\
\hline 32 & 103 & $20^{\star}$ & 13 & - & 0.08 & 0.08 \\
\hline 33 & 116 & 31 & I I & $I \cdot 7$ & 0.09 & 0.08 \\
\hline 34 & 170 & 23 & I I & $I \cdot 5$ & 0.10 & 0.08 \\
\hline 35 & II 5 & 38 & 13 & - & 0.08 & 0.07 \\
\hline
\end{tabular}

* Pulmonary arterial wedge pressures. $\dagger$ See text.

TABLE 2 Correlation between haemodynamic findings and A2-OS interval in 35 cases of mitral stenosis

\footnotetext{
Left atrial ' $V$ ' wave pressure/A2-OS $\quad r=-0.59 \quad p<0.001$

LV systolic pressure/A2-OS $\quad r=0.6 I \quad p<0.00 I$

LV pressure minus LA' ' $V$ ' pressure/A2-OS

Mean mitral diastolic gradient/A2-OS

Mitral valve area/A2-OS $r=0.78 \quad p<0.00 \mathrm{I}$ $r=-0.53 \quad p<0.01$ $\begin{array}{ll}r=-0.53 & p<\end{array}$
}

LA pressure will shorten this interval. A steeper rate of fall of $L V$ pressure will shorten A2-OS.

Because of the great change in A2-OS 


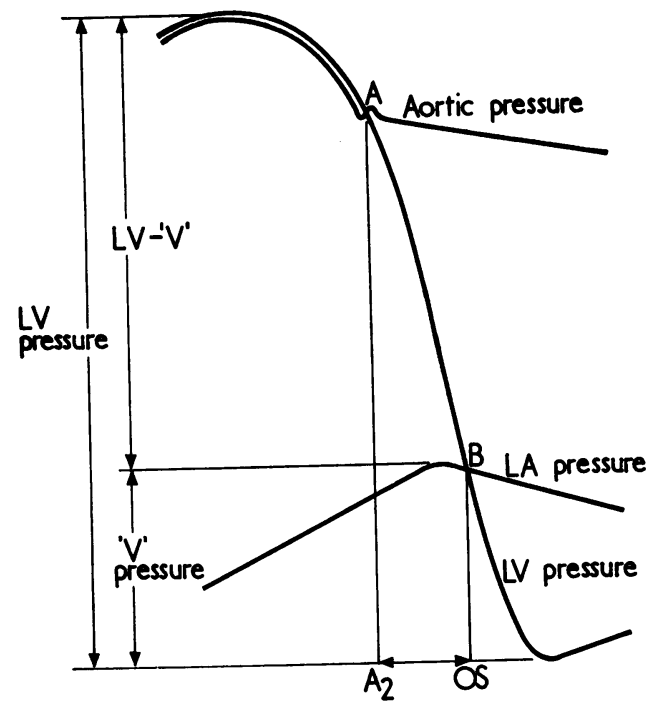

FIG. I Diagrammatic representation of haemodynamic factors affecting A2-OS interval.

with change in LV pressure a method was devised to compensate for this latter variable. Fig. 2 is a diagrammatic approximation of the pressure changes in the left ventricle and left atrium during the A2-OS interval. The value $K$ indicates the time taken for the left ventricular pressure to fall to zero from the end of systole. It is assumed to be constant for any one patient if left ventricular pressure changes are not gross.

As shown in Fig. 2,

$$
\begin{gathered}
\frac{L V-' V '}{L V}=\frac{A 2-O S}{K} \\
\therefore A 2-O S=\frac{L V-' V^{\prime}}{L V} \times K \\
\therefore \mathrm{K}=A 2-O S \times \frac{L V}{L V-' V '}
\end{gathered}
$$$$
\text { (Similar triangles) }
$$
ste

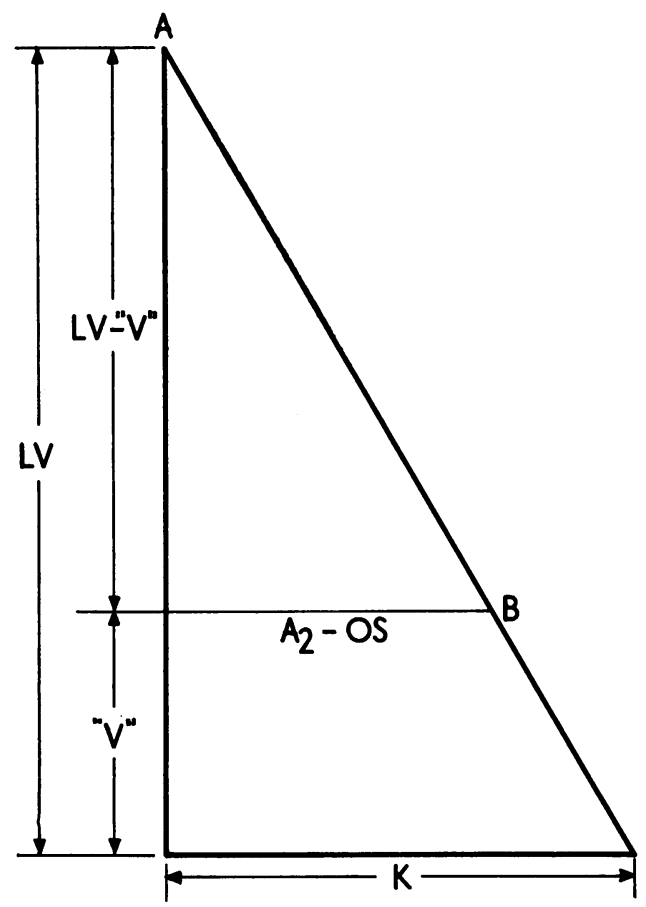

FI G. : Diagrammatic representation of pressure changes occurring during A2-OS interval (see text).

with atrial ' $\mathrm{V}$ ' wave pressure, mitral diastolic gradient, and mitral valve area. As indicated in Table 3, when the LA ' $V$ ' mean

TABLE 3 Correlation between haemodynamic findings and A2-OS corrected to LV systolic pressure of $100 \mathrm{~mm} . \mathrm{Hg}$ in 35 cases of mitral stenosis

$$
\begin{array}{ll}
\begin{array}{l}
\text { Left atrial ' } V \text { ' wave pressure/ } \\
\text { A2-OS }
\end{array} & r=-0.68 \quad p<0.00 I \\
\begin{array}{ll}
\text { Mean mitral diastolic } \\
\text { gradient/A2-OS }
\end{array} & r=-0.58 \quad p<0.00 I \\
\text { Mitral valve area/A2-OS } & r=0.23 \quad N S
\end{array}
$$

mitral diastolic gradient and mitral valve area were correlated with a corrected A2-OS interval, the degree of correlation improved in each case, though again there was no significant correlation with mitral valve area.

\section{Discussion}

The value of having a clinical method of assessing the degree of mitral valve stenosis is obvious. Gorlin and Gorlin (195I) introduced a mathematical formula to estimate mitral valve area. Calculation of the mitral pressure, one could presume that the corrected A2-OS may give a better correlation 
valve area requires knowledge of 3 parameters: the cardiac output, the diastolic time interval, and the mean mitral valve gradient. The average flow across the valve during diastole gives an indication of the size of the opening.

Wells in 1954 was one of the first to suggest that the A2-OS interval could be used to indicate the degree of stenosis. Other workers investigated this relation and correlated stenotic severity with other intermediate parameters.

Because of the conflicting results the relation of these factors is still uncertain. This is mainly due to the small numbers used in early studies. Our findings using simple statistical analysis show that LA ' $V$ ' and mean mitral diastolic gradient correlate well with A2-OS, but that mitral valve area correlates poorly. These results illustrate the difficulty involved in comparing two haemodynamic factors (i.e. A2-OS and mitral valve area) when the errors of measurement and other haemodynamic variables also play a part.

A2-OS is determined by left atrial ' $V$ ' pressure, systolic ventricular pressure, and rate of relaxation of left ventricle. To determine mitral valve area, both the cardiac output and diastolic interval must be known as well as the mean mitral diastolic gradient. Therefore all these factors must be considered if the A2-OS interval is to correlate well with the mitral valve area. Moreover, the left atrial ' $\mathrm{V}$ ' pressure is only a rough indicator of the mean mitral gradient. The exponential decay of the pressure gradient from the start of diastole, the inertia of the blood in the left atrium, and the effect of atrial systole or its absence all contribute to the value measured as mitral diastolic mean gradient. Thus, though on theoretical grounds one may imply a relation between A2-OS and mitral valve area, it becomes quickly obvious that as other factors come into effect at each particular step in the process the correlation between the two becomes tenuous.

Our results agree with the findings of Bayer et al. (1956), Julian and Davies (1957), and Oriol et al. (1965), that the left ventricular pressure plays a major role in determining the A2-OS interval. We have attempted to eliminate this factor from the comparisons of $\mathrm{A}_{2}-\mathrm{OS}$ to the other variables by fixing the $\mathrm{LV}$ pressure. This resulted in better correlations of A2-OS with these variables. Left ventricular pressure itself, however, is not a completely independent variable as it also reflects cardiac output and thus mitral valve area to some extent.

\section{Conclusion}

We have found that the A2-OS interval by itself is a poor indicator of severity of stenosis. This is partly due to the wide range of A2-OS intervals which occur within a sample group and to the experimental error inherent in any measurement. However, the specific haemodynamic variables which are unaccounted for when only the opening snap is measured are probably the most important causes of the poor correlation.

These factors include the left ventricular pressure, the rate of relaxation of the left ventricle, and the exponential rate of decrease of left atrial pressure during diastole. Other factors include the compliance of the left ventricle, the diastolic interval, and the cardiac output. Finally, two other factors which may be important are the increased flow produced during atrial systole and the effects of inertia and momentum of the blood volumes in determining the pressures and flow across the mitral valve.

This study was carried out by one of us (R. E.) as an undergraduate elective project for the Monash University Medical School.

\section{References}

Bayer, O., Loogen, F., and Wolter, H. H. (1956). The mitral opening snap in the quantitative diagnosis of mitral stenosis. American Heart fournal, 5r, 234.

Craige, E. (1957). Phonocardiographic studies in mitral stenosis. New England fournal of Medicine, 257, 650 .

Davies, J. P. H. (1967). A simple phonocardiographic formula for predicting left atrial pressure in mitral stenosis. British Heart fournal, 29, 843.

Delman, A. J., Gordon, G. M., Stein, E., and Escher, D. J. W. (1966). The second sound - mitral opening snap (A2-OS) interval during exercise in the evaluation of mitral stenosis. Circulation, 33, 399.

Di Bartolo, G., Núñez-Dey, D., and Bendezú-Prieto, J. (I962). Left heart studies in mitral stenosis with special reference to intracardiac phonocardiography. American fournal of Cardiology, 10, 93.

Gorlin, R., and Gorlin, S. G. (I95I). Hydraulic formula for calculation of the area of the stenotic mitral valve, other cardiac valves, and central circulatory shunts. American Heart fournal, 4I, I.

Julian, D., and Davies, L. G. (1957). Heart sounds and intracardiac pressures in mitral stenosis. British Heart fournal, 19, 486.

Leo, T., and Hultgren, H. (I959). Phonocardiographic characteristics of tight mitral stenosis. Medicine, 38, 85 .

Oriol, A., Palmer, W. H., Nakhjavan, F., and McGregor, M. (1965). Production of left atrial pressure from the second sound-opening snap interval. American fournal of Cardiology, 16, 184.

Proctor, M. H., Walker, R. P., Hancock, E. W., and Abelmann, W. H. (1958). The phonocardiogram in mitral valvular disease. American fournal of Medicine, 24, 86I. 
Rich, C. B. (1959). The relationship of heart sounds to left atrial pressure. Canadian Medical Association fournal, 81, 800 .

Surawicz, B., Mercer, C., Chlebus, H., Reeves, J. T., and Spencer, F. C. (1966). Role of the phono- cardiogram in evaluation of the severity of mitral stenosis and detection of associated valvular lesions. Circulation, 34, 795.

Wells, B. (1954). The assessment of mitral stenosis by phonocardiography. British Heart fournal, 16, 26I. 